\title{
SEASONAL VARIATION IN THE COMPOSITION OF VOLATILE OILS FROM Schinus terebinthifolius RADDI
}

Luiz Cláudio Almeida Barbosa*, Antônio Jacinto Demuner and Alan Dumont Clemente

Departamento de Química, Universidade Federal de Viçosa, 36571-000 Viçosa - MG, Brasil

Vanderlúcia Fonseca de Paula

Departamento de Química e Exatas, Universidade Estadual do Sudoeste da Bahia, Campus de Jequié,

45206-510 Jequié - BA, Brasil

Faiz M. D. Ismail

The School of Pharmacy and Chemistry, Liverpool John Moores University, Byrom Street, Liverpool L3 3AF, United Kingdom

Recebido em 26/2/07; aceito em 11/5/07; publicado na web em 16/10/07

\begin{abstract}
Essential oils from leaves, ripe and unripe fruits of Schinus terebinthifolius growing in Brazil were investigated. Oil content from either ripe or unripe fruits was similar (4.65\% and 3.98\%, respectively). Sesquiterpenes (from $78.0 \%$ to $90.4 \%$ ) dominated the oil content of both leaves and unripe fruit. The essential oils were tested in vitro for their allelopathic activity on germination and radicle growth of Lactuca sativa and Cucumis sativus at 1,000 and $10,000 \mu \mathrm{g} \mathrm{mL}^{-1}$ concentrations. The three samples tested were more active in inhibiting the radicle growth for L. sativa (88.6-92.4\%) than for C. sativus (50.5-84.5\%) at $10,000 \mu \mathrm{g} \mathrm{mL}^{-1}$ concentration.
\end{abstract}

Keywords: Schinus terebinthifolius; essential oils; allelopathic activity.

\section{INTRODUCTION}

Schinus terebinthifolius Raddi (Anacardiaceae) is a perennial tree indigenous to the coast of Brazil, and has been introduced into other South American countries, parts of Central America, Bermu$\mathrm{da}$, the Bahama Islands, the West Indies, Florida, Southern Arizona, California, Hawaii, Mediterranean Europe, North Africa, Southern Asia and South Africa. ${ }^{1-3}$ It is known by a variety of common names including "aroeira-vermelha", "aroeira-pimenteira", Brazilian pepper, Christmas-berry, pink-pepper, poivre rose. ${ }^{1,4,5}$ In Brazil, $S$. terebinthifolius dried fruits are also marketed as a substitute for black pepper and is occasionally found as a pink seeded adulterant in Piper nigrum (Black Pepper) in other countries. Many medicinal properties have been attributed to this plant, such as antioxidant, ${ }^{6-8}$ woundhealing, ${ }^{9}$ antitumor ${ }^{10}$ and antimicrobial ${ }^{11,12}$ activities. In Brazil, the extract of stem bark is widely used as an anti-inflammatory and to heal over or cicatrize wounds. ${ }^{13}$ Specifically, the crushed, dried leaves are applied as antiseptic poultices upon skin ulcers. Relief from bronchitis and other respiratory ailments is treated by leaf infusions. Interestingly, the juice of macerated roots is considered effective in treating ganglionic tumors. Although this plant is widely used for medicinal purposes, mutagenic (cytotoxic) activity detected within extracts from its stem bark ${ }^{14}$ as well as hypersensitivity to the volatile oil warrant considerable caution in indiscriminate use of this natural remedy until a full toxicological profile is available.

Despite the aforementioned benefits, the Brazilian pepper tree is often undesirable outside its native range. Since its introduction into the United States in the late $19^{\text {th }}$ century as an ornamental tree, it has been recognized as an invasive, exotic plant widely found in Florida and Hawaii that out competes native species. ${ }^{1,2,15,16}$ Therefore, S. terebinthifolius has been considered one of the most serious biological threats to the Everglades upland ecosystem, and classified in Category I of the Florida Exotic Pest Plant Council's List of Invasive Species. A plant in that category is defined as being

*e-mail: lcab@ufv.br able to alter the structure and function of native communities. ${ }^{17}$ In a recent, study the allelopathic effects of Brazilian pepper aqueous extracts upon germination and growth of selected Florida native plants has been demonstrated..$^{15}$

The occurrence of deleterious biochemical interactions among higher plants, known as allelopathy, is generally considered a significant ecological factor in determining the structure, variety and composition of plant communities. ${ }^{18} \mathrm{~A}$ variety of allelochemicals are known, including components from essential oils, that both inhibit seed germination as well as plant growth. ${ }^{18-22}$ Some of the essential oils considered to present allelopathic effects can be extracted from Tagetes minuta L. (Compositae), Schinus areira L. (Anacardiaceae), ${ }^{18}$ Ruta graveolens L. (Rutaceae), ${ }^{19}$ Rosmarinus officinalis L., Thymus vulgaris L. (Labiatae) Satureja montana L (Lamiaceae) ${ }^{20}$ and Conyza albida Willd. (Compositae). ${ }^{21}$

The essential oils from leaves, flowers and fruits of $S$. terebinthifolius from different locations have been previously investigated and some variation on their chemical composition have been observed. ${ }^{10,23-26}$ Most of the oil samples analyzed revealed $\alpha$ pinene (15.01-51.82\%) as the major component, especially those originating from India. ${ }^{23-26}$ Other major constituents were $\alpha$ phellandrene, elixene, germacrene $\mathrm{D}$, limonene and $p$-cymene.

This investigation details the essential oil composition of both leaves and fruits from S. terebinthifolius collected in Viçosa - Brazil. In addition, the allelopathic properties of the oil extracts obtained upon seed germination and radicle growth of Lactuca sativa (lettuce) and Cucumis sativus (cucumber) are reported.

\section{EXPERIMENTAL}

\section{Plant material and commercial oil}

The aerial parts (leaves and fruits) of S. terebinthifolius were collected from wild plants found in the campus of Universidade Federal de Viçosa, Minas Gerais State (Brazil). A voucher specimen (VIC 30839) was deposited in the Herbarium of the Botany 
Department at the same university. Plant samples were collected at intervals of 30 days, starting in October 2004 and ending in September 2005. In October 2004, when the plants started flowering, two samples of leaves were collected, one from branches with flowers (ILO) and another one from branches without flowers (LO). In December 2004 and February 2005, samples (100 g each) of both unripe and ripe fruits were collected, respectively. A sample of commercial oil (CO), extracted by supercritical fluid extract of fruits of S. terebinthifolius (trade mark FLAVEX ${ }^{\circledR}$ ), was procured from French commercial sources and analyzed as a comparator.

\section{Essential oil extraction}

Oil extraction of fresh samples of both leaves and fruits of $S$. terebinthifolius ( $20 \mathrm{~g}$ of each component), over a three hour period, was achieved using a Clevenger apparatus. ${ }^{27}$ The resulting oils obtained were weighed and the yields were expressed relative to the dry matter content of either leaves or fruits. Leaf dry weight was calculated by drying each sample $\left(2 \mathrm{~g}\right.$, held at $103 \pm 2{ }^{\circ} \mathrm{C}$ for $24 \mathrm{~h}$ ) according to published methods. ${ }^{28}$ Each determination was carried out in triplicate.

In order to evaluate the influence of the extraction time on the oil composition, a sample of ripe fruit $(20 \mathrm{~g})$ was subjected to the aforementioned oil extraction procedure and the oil was collected at intervals of $20 \mathrm{~min}$, over a three hour period. This experiment was also carried out in triplicate.

\section{Gas chromatography-mass spectrometry (GC-MS)}

The essential oil samples were analyzed by both gas chromatography (Shimadzu GC-17A equipped with a flame ionization detector (FID) and by gas chromatography-mass spectrometry (GC-MS); Shimadzu GCMS-QP5050A apparatus, equipped with an ion trap detector, operating in electron impact mode (70 eV); scan speed 1000; scan interval 0.50 and fragments were scanned between 45 to $450 \mathrm{Da}$. Identical chromatographic conditions were used in both analyses: fused silica capillary column $(30 \mathrm{~m} \mathrm{x}$ $0.22 \mathrm{~mm})$ with a DB5 bonded phase $(0.25 \mu \mathrm{m}$ film thickness $)$; under the following conditions: carrier gas $\mathrm{N}_{2}$ (GC) or $\mathrm{He}$ (GC-MS), flow rate $1.8 \mathrm{~mL} \mathrm{~min}^{-1}$; injector temperature $220{ }^{\circ} \mathrm{C}$, detector temperature $240{ }^{\circ} \mathrm{C}$; column temperature was programmed to hold at $60{ }^{\circ} \mathrm{C}$ (isothermal for $2 \mathrm{~min}$ ), then ramped by $3{ }^{\circ} \mathrm{C} \mathrm{min}^{-1}$, to $240{ }^{\circ} \mathrm{C}$, then isothermal at $240{ }^{\circ} \mathrm{C}$ for $15 \mathrm{~min}$; injection volume was $1.0 \mu \mathrm{L}(1 \%$ solution in $\mathrm{CH}_{2} \mathrm{Cl}_{2}$ ), in split mode, with ratio of 1:10. Each component was identified by comparison of acquired mass spectrum with reference data from a commercially available database (Wiley $330.000)$, literature data ${ }^{29}$ and also by its experimental Kovat's retention index $(\mathrm{KI})$ calculated from a $\mathrm{C}_{9}-\mathrm{C}_{24} n$-alkanes series. ${ }^{29,30}$ The chemical components amounts were calculated from the $\mathrm{GC}-$ $17 \mathrm{~A}$ peak area, and the results presented are the average of three replicate experiments.

\section{Germination and growth assay}

Bioassays were carried out as previously described, ${ }^{31}$ with seeds of Lactuca sativa and Cucumis sativus. Essential oils solutions from fresh leaves, unripe and ripe fruits were prepared at concentrations of 1,000 and $10,000 \mu \mathrm{g} \mathrm{mL}^{-1}$ in dichloromethane. Assays were conducted in a $90 \times 15 \mathrm{~mm}$ glass Petri dishes lined with 1 sheet of Whatman $\mathrm{N}^{\circ} 1$ filter paper and sealed with Parafilm ${ }^{\circledR}$. To each dish was added $3 \mathrm{~mL}$ of each solution and the solvent was evaporated before addition of $3 \mathrm{~mL}$ of water followed by 20 seeds of $L$. sativa or C. sativus. Assays were carried out at $25^{\circ} \mathrm{C}$ under artificial fluorescent light $(8 \times 40 \mathrm{~W})$ in an incubator for 3 days. Subsequently, after which germination was scored and the radicle length was measured. Seeds were considered to have germinated if a radicle protruded at least 1 $\mathrm{mm}$. A control experiment was carried out under the same conditions described but using only water instead of the test oil. Each bioassay was replicated 5 times in a complete randomized design. The percentage of root growth inhibition was calculated with respect to the root length of the water-treated control. The results were analyzed by the Tukey's test at 0.05 probability level.

\section{RESULTS AND DISCUSSION}

A preliminary study was undertaken to ascertain optimal distillation time on both the yield and composition of the oil obtained. Consequently, hydrodistillation of the ripe fruits was carried out during a period of $3 \mathrm{~h}$ and the oil obtained was collected every 20 $\min$. After $3 \mathrm{~h}$ of extraction, the amount of oil obtained corresponded to $4.65 \% \mathrm{w} / \mathrm{w}$, in relation dry fruit weight. A major proportion (78\%) of the total oil present in the fruits was extracted within $20 \mathrm{~min}$ (Figure 1), but the last $20 \mathrm{~min}$ (from 160 to $180 \mathrm{~min}$ ) only provided a small amount $(2 \%)$ of the total oil extracted.

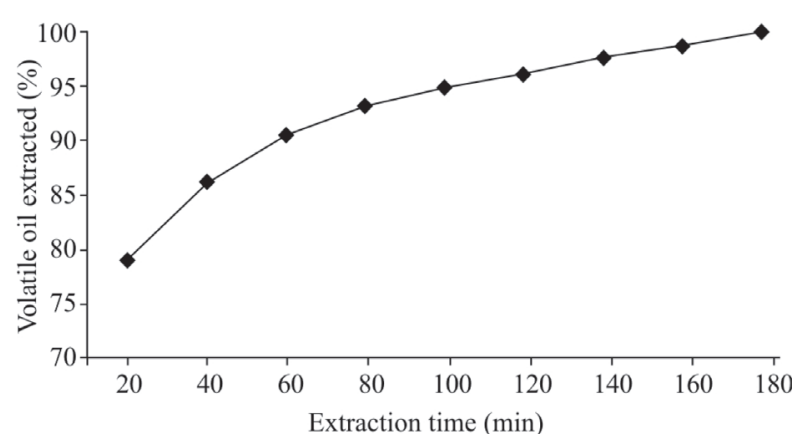

Figure 1. Yield of volatile oil with extraction time

The 27 major constituents positively identified in each oil fraction are shown in Table 1. For the first two fractions (20 and $40 \mathrm{~min}$ ) the compounds identified corresponded to more than $90 \%$, relative to the total chromatogram area. With longer extraction time, the amount of oil extracted decreased and the percentage of compounds identified was also smaller, reducing to around $80 \%$ of the total chromatogram peaks areas for the last fraction (160 to $180 \mathrm{~min}$ ).

Conveniently, the oil components can be grouped into four major classes: hydrocarbon monoterpenes (HM); oxygenated monoterpenes (OM); hydrocarbon sesquiterpenes (HS) and oxygenated sesquiterpenes (OS). The percentage of area corresponding to each compound class was calculated for each fraction (Figure 2). In general, the lighter compounds (HM) were extracted almost completely during the first 20 min (94\%), and a smaller amount (22\%) was obtained during the last $20 \mathrm{~min}$ of extraction.

The percentage of OM was very small in all fractions $(<3 \%)$. The HS and OS respectively were present in $5 \%$ and $0.8 \%$ respectively in the oil extracted during the first $20 \mathrm{~min}$, but was higher (22 and 53\%) in the last fraction (160 to $180 \mathrm{~min}$ ).

From the results presented in Figure 1 and 2, a total extraction time of 180 min appeared optimal and was chosen for all subsequent experiments, as it allowed most, if not complete extraction of the less volatile oxygenated sesquiterpenes.

Using this extraction procedure $(3 \mathrm{~h})$ for the leaves collected from branches without flowers (LO), the oil content was $0.44 \% \mathrm{w} / \mathrm{w}$, and for those from branches that were flowering (ILO), the amount found 
Table 1. Major terpenoid components identified in the essential oil extracted from ripe fruits. The total extraction time was 180 min and samples were collected every $20 \mathrm{~min}$

\begin{tabular}{|c|c|c|c|c|c|c|c|c|c|c|}
\hline \multirow[t]{3}{*}{ Compounds } & \multirow[t]{3}{*}{$\mathrm{IK}^{*}$} & \multicolumn{9}{|c|}{ Time (min) } \\
\hline & & 20 & 40 & 60 & 80 & 100 & 120 & 140 & 160 & 180 \\
\hline & & \multicolumn{9}{|c|}{ Chromatographic area $(\%)$} \\
\hline$\alpha$-Thujene & 933 & 0.20 & 0.14 & 0.15 & 0.14 & 0.10 & 0.16 & 0.20 & 0.16 & 0.14 \\
\hline$\alpha$-Pinene & 940 & $14.31^{\#}$ & 8.28 & 6.48 & 5.51 & 3.12 & 2.54 & 2.56 & 2.13 & 1.80 \\
\hline Sabinene & 977 & 3.49 & 1.34 & 0.93 & 1.28 & 0.55 & 0.42 & 0.39 & 0.39 & 0.26 \\
\hline$\beta$-Pinene & 980 & 3.47 & 2.07 & 1.67 & 1.81 & 0.99 & 0.82 & 0.87 & 0.74 & 0.70 \\
\hline$\beta$-Myrcene & 991 & 5.69 & 3.59 & 2.80 & 3.83 & 1.63 & 1.29 & 1.30 & 1.08 & 0.96 \\
\hline$\alpha$-Phellandrene & 1004 & 12.94 & 9.16 & 7.45 & 9.12 & 4.58 & 3.68 & 3.76 & 3.17 & 2.88 \\
\hline$\Delta^{3}$-Carene & 1011 & 30.09 & 21.74 & 17.15 & 14.27 & 10.23 & 7.87 & 7.80 & 6.42 & 5.82 \\
\hline$p$-Cymene & 1026 & 1.32 & 0.95 & 0.85 & 0.84 & 0.69 & 0.60 & 0.74 & 0.60 & 0.61 \\
\hline$\beta$-Phellandrene & 1031 & 18.51 & 13.85 & 11.17 & 7.73 & 7.07 & 5.62 & 5.79 & 4.79 & 4.49 \\
\hline$\alpha$-Terpinolene & 1088 & 1.05 & 1.04 & 0.89 & 0.79 & 0.61 & 0.51 & 0.53 & 0.47 & 0.44 \\
\hline Terpin-4-ol & 1177 & 0.17 & 0.86 & 1.11 & 1.23 & 1.57 & 1.75 & 2.18 & 2.17 & 2.24 \\
\hline$\delta$-Elemene & 1339 & 0.15 & 0.59 & 0.57 & 0.43 & 0.42 & 0.37 & 0.28 & 0.32 & 0.29 \\
\hline$\alpha$-Copaene & 1376 & 0.13 & 0.34 & 0.35 & 0.33 & 0.34 & 0.31 & 0.33 & 0.32 & 0.30 \\
\hline$\beta$-Elemene & 1391 & 0.49 & 0.88 & 0.96 & 1.88 & 0.89 & 0.86 & 0.69 & 0.80 & 0.74 \\
\hline (E)-Caryophyllene & 1418 & 1.23 & 3.76 & 3.80 & 1.87 & 3.32 & 3.17 & 2.60 & 2.79 & 2.54 \\
\hline$\alpha$-Humulene & 1454 & 0.09 & 0.40 & 0.47 & 4.28 & 1.09 & 1.05 & 0.84 & 0.97 & 0.85 \\
\hline Germacrene D & 1481 & 2.16 & 8.67 & 8.73 & 5.49 & 7.39 & 6.55 & 4.86 & 5.22 & 4.39 \\
\hline$\alpha$-Muurolene & 1499 & 0.30 & 1.65 & 1.76 & 3.57 & 2.64 & 2.68 & 1.70 & 1.77 & 1.62 \\
\hline$\gamma$-Cadinene & 1513 & 0.14 & 0.42 & 0.67 & 0.78 & 0.98 & 1.04 & 0.93 & 1.07 & 1.02 \\
\hline$\delta$-Cadinene & 1524 & 0.29 & 2.93 & 4.87 & 6.34 & 6.92 & 7.05 & 6.37 & 6.77 & 6.33 \\
\hline Elemol & 1548 & 0.31 & 3.43 & 6.32 & 5.64 & 11.33 & 12.93 & 12.80 & 13.64 & 13.62 \\
\hline Germacrene B & 1557 & 0.09 & 0.59 & 0.76 & 0.77 & 0.85 & 0.88 & 0.77 & 0.79 & 0.69 \\
\hline Caryophyllene oxide & 1581 & 0.06 & 0.37 & 0.62 & 0.67 & 0.86 & 0.89 & 0.81 & 0.83 & 0.77 \\
\hline Germacrene D-4-ol & 1631 & 0.07 & 0.58 & 1.38 & 1.94 & 3.19 & 4.02 & 4.59 & 5.09 & 5.33 \\
\hline epi- $\alpha$-Cadinol & 1642 & 0.05 & 0.53 & 1.31 & 3.19 & 3.04 & 3.76 & 4.17 & 4.50 & 4.56 \\
\hline$\alpha$-Cadinol & 1655 & 0.09 & 1.48 & 3.79 & 4.74 & 9.38 & 12.07 & 14.12 & 15.50 & 16.26 \\
\hline$\alpha$-Bisabolol & 1684 & 0.08 & 0.65 & 0.87 & 0.79 & 0.89 & 0.78 & 0.94 & 0.69 & 0.43 \\
\hline Total identified & & 96.97 & 90.29 & 87.88 & 89.26 & 84.67 & 83.67 & 82.92 & 83.19 & 80.36 \\
\hline
\end{tabular}

*IK: Kovats retention index. \# Bold values indicate compounds present in larger quantities.

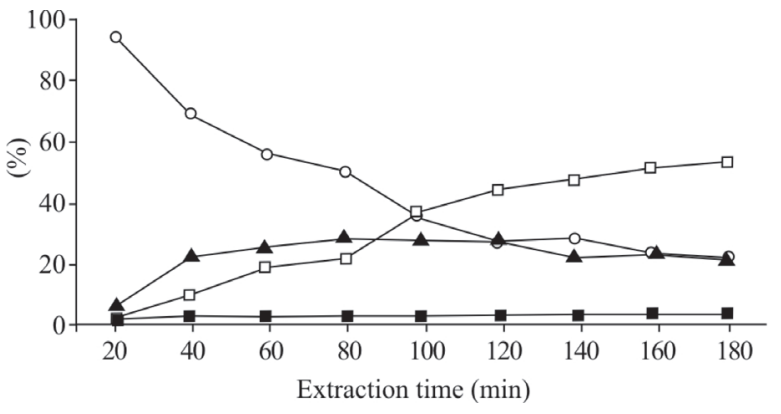

Figure 2. Percentage of the various classes of compounds present in the volatile oil from ripe fruits at different extraction times: $H M(\mathrm{O}), O M(\mathbf{\square})$, $H S(\mathbf{\Delta})$ and $O S(\square)$

was reduced to $0.11 \% \mathrm{w} / \mathrm{w}$. We suggest that reduction in the oil content in the leaves is due to a change in metabolism, with the plant expending more energy and resources during the flowering process, for a parallel can be dawn the perennial rosemary (Rosmarinus officinalis), whose leaves show some variation in the oil content during the flowering stage. $^{32}$

Analyses revealed that the unripe and ripe fruits contained 3.98 and $4.65 \% \mathrm{w} / \mathrm{w}$ of oil, respectively. Chromatographic and spectrometric analysis of the four oil samples obtained (LO, ILO,
UFrO, RFrO) allowed the identification of a total of 57 compounds (Table 2). Both quantitative and qualitative differences were detected between samples. For instance, within sample LO, the major constituents were germacrene D $(33.80 \%),(E)$-caryophyllene $(12.25 \%)$, $\beta$-pinene $(5.18 \%)$ and $(Z)-\beta$-ocimene $(5.16 \%)$; for sample ILO they were bicyclogermacrene (20.82\%), germacrene D (16.06\%), and $\beta$-elemene $(5.92 \%)$. In contrast, the oil from unripe fruits had the following major constituents: $\alpha$-cadinol $(20.60 \%), \delta$-cadinene (15.48\%), $\beta$-pinene $(10.21 \%)$ and epi- $\alpha$-muurolol $(9.89 \%)$.

Oil compositions between unripe and ripe fruits differed (Table 2). Compounds were grouped into monoterpenes and sesquiterpenes and their percentage in each sample are presented in Figure 3.

Sesquiterpenes are major secondary metabolites within these leaves ( 83.60 and $90.40 \%$ for LO and ILO samples, respectively) and unripe fruits $(78.0 \%)$. A sample of commercial oil of $S$. terebinthifolius $\left(\mathrm{FLAVEX}^{\circledR}\right.$ ) was analyzed for comparative purposes and the results are shown in Table 2 and Figure 3. Ripe fruits (RFrO) and the commercial oil (CO) are both rich in monoterpenes (90.00 and $79.50 \%$, respectively). However, a closer inspection of Table 2 reveals major differences in their relative chemical composition. For instance, RFrO sample has $29.22 \%$ of $\Delta^{3}$-carene while the commercial oil $(\mathrm{CO})$ has only $6.32 \%$. In contrast, $\alpha$-pinene, $\alpha$ phellandrene and germacrene D are higher in the CO sample (18.82, 23.55 and $11.89 \%$, respectively) compared to the RFrO sample $(12.94,13.04$ and $3.09 \%$, respectively). These results suggest that essential oils of the leaves and unripe fruits cannot be used as 
Table 2. Chemical composition of the essential oil from aerial parts ${ }^{\#}$

\begin{tabular}{|c|c|c|c|c|c|c|}
\hline \multirow[t]{2}{*}{ Compounds } & $\mathrm{KI}^{*}$ & $\mathrm{LO}$ & ILO & UFrO & $\mathrm{RFrO}$ & $\mathrm{CO}$ \\
\hline & \multicolumn{6}{|c|}{ Area $(\%)$} \\
\hline$\alpha$-Thujene & 933 & - & - & - & 0.21 & 0.20 \\
\hline$\alpha$-Pinene & 940 & 1.07 & - & 3.06 & 12.94 & 18.82 \\
\hline Sabinene & 977 & 0.08 & - & 0.40 & 3.25 & 2.33 \\
\hline$\beta$-Pinene & 980 & 5.18 & 0.09 & 10.21 & 5.02 & 2.54 \\
\hline Myrcene & 991 & 0.05 & - & 0.41 & - & 1.99 \\
\hline$\alpha$-Phellandrene & 1004 & 1.14 & - & 0.14 & 13.04 & 23.55 \\
\hline$\Delta^{3}$-Carene & 1011 & - & - & - & 29.22 & 6.32 \\
\hline$p$-Cymene & 1026 & 0.06 & - & - & 0.20 & 4.03 \\
\hline$\beta$-Phellandrene & 1031 & 0.12 & 0.07 & 2.49 & 18.08 & 16.88 \\
\hline (Z)- $\beta$-Ocimene & 1040 & 5.16 & - & - & - & - \\
\hline$\gamma$-Terpinene & 1061 & 0.70 & - & 0.10 & 0.25 & - \\
\hline Terpinolene & 1088 & 0.12 & - & 0.10 & - & 0.64 \\
\hline Linalool & 1097 & 0.20 & 0.11 & - & 1.04 & - \\
\hline Borneol & 1165 & 0.05 & 0.22 & 0.02 & - & - \\
\hline Terpin-4-ol & 1177 & 0.81 & 1.17 & 0.62 & 0.29 & - \\
\hline$\alpha$-Terpineol & 1189 & 3.05 & 5.35 & 1.47 & - & - \\
\hline$\delta$-Elemene & 1339 & 2.61 & - & - & - & - \\
\hline$\alpha$-Copaene & 1376 & 0.53 & 0.34 & 0.29 & - & 0.32 \\
\hline$\beta$-Bourbonene & 1384 & 0.12 & 0.29 & - & - & - \\
\hline$\beta$-Elemene & 1391 & 1.16 & 5.92 & 1.15 & 0.32 & - \\
\hline$\alpha$-Gurjunene & 1409 & 0.08 & 0.08 & 1.80 & - & - \\
\hline (E)-Caryophyllene & 1418 & 12.25 & 2.93 & 4.78 & 1.45 & 2.34 \\
\hline$\beta$-Gurjunene & 1429 & 0.24 & 0.23 & - & - & - \\
\hline$\gamma$-Elemene & 1433 & 0.15 & 0.21 & - & - & - \\
\hline Aromadendrene & 1439 & 0.04 & 0.77 & - & - & - \\
\hline$\alpha$-Humulene & 1454 & 1.20 & 0.65 & 1.26 & 0.19 & 0.14 \\
\hline$(E)$ - $\beta$-Farnesene & 1458 & - & 0.23 & 0.62 & - & - \\
\hline Alloaromadendrene & 1461 & - & 0.86 & 0.85 & - & - \\
\hline$\beta$-Chamigrene & 1475 & 0.43 & 1.29 & - & - & - \\
\hline$\gamma$-Muurolene & 1476 & - & - & 0.80 & - & 0.07 \\
\hline Germacrene D & 1481 & 33.80 & 16.06 & 5.19 & 3.09 & 11.89 \\
\hline$\beta$-Selinene & 1487 & 0.17 & 1.43 & - & - & - \\
\hline Bicyclogermacrene & 1495 & 4.59 & 20.82 & - & 0.57 & 1.40 \\
\hline$\alpha$-Muurolene & 1499 & 0.95 & - & 2.85 & - & - \\
\hline Germacrene A & 1504 & 0.78 & 4.81 & 0.63 & - & - \\
\hline$\gamma$-Cadinene & 1513 & 0.55 & 0.31 & 1.58 & - & - \\
\hline$\delta$-Cadinene & 1524 & 2.95 & 3.11 & 15.48 & 1.22 & 0.32 \\
\hline Cadina-1,4-diene & 1532 & 0.13 & 0.20 & 1.07 & - & - \\
\hline$\alpha$-Cadinene & 1537 & 0.21 & 0.09 & 0.37 & 0.15 & - \\
\hline$\alpha$-Calacorene & 1542 & 0.18 & 0.65 & - & - & - \\
\hline Elemol & 1548 & - & - & - & - & 1.88 \\
\hline Germacrene-B & 1557 & 2.58 & - & - & 0.22 & 0.64 \\
\hline (E)-Nerolidol & 1563 & 0.17 & 0.32 & - & - & - \\
\hline Ledol & 1567 & - & 0.72 & 0.53 & - & - \\
\hline Germacrene D-4-ol & 1574 & - & - & 2.36 & - & - \\
\hline Spathulenol & 1576 & 0.10 & 4.04 & - & 0.21 & 1.11 \\
\hline Caryophyllene oxide & 1581 & - & - & 0.21 & - & 0.31 \\
\hline Globulol & 1583 & 0.58 & 3.14 & - & - & - \\
\hline Viridiflorol & 1591 & 0.69 & 2.69 & 0.98 & - & - \\
\hline Rosifoliol & 1600 & - & 1.20 & - & - & - \\
\hline 1-epi-Cubenol & 1627 & 0.19 & 0.56 & 0.62 & - & - \\
\hline Isospathulenol & 1628 & 1.84 & - & - & - & - \\
\hline$\gamma$-Eudesmol & 1631 & 0.35 & 0.44 & - & - & - \\
\hline epi- $\alpha$-Muurolol & 1642 & 2.45 & - & 9.89 & 0.35 & - \\
\hline$\alpha$-Muurolol & 1646 & 2.44 & 2.98 & 1.58 & & - \\
\hline$\alpha$-Cadinol & 1655 & 2.73 & 5.32 & 20.60 & 1.21 & - \\
\hline$\alpha$-Bisabolol & 1684 & 0.80 & 0.31 & 0.42 & 0.26 & - \\
\hline TOTAL & & 95.83 & 90.01 & 94.93 & 92.78 & 97.72 \\
\hline
\end{tabular}

*KI - Kovats retention index; \# Oils from fresh leaves from LO, ILO, UFrO, RFrO and CO. 


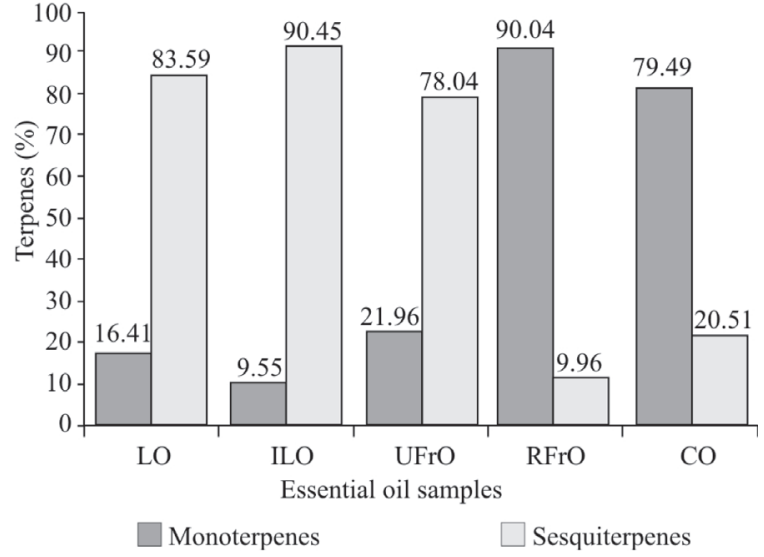

Figure 3. Percentage of monoterpenes and sesquiterpenes in the essential oil obtained from $\mathrm{LO}, \mathrm{ILO}, \mathrm{UFrO}, \mathrm{RFrO}$ and $\mathrm{CO}$

commercial substitutes for FLAVEX ${ }^{\circledR}$. Conversely, the oil from ripe fruits, obtained by steam distillation, from plants native to the Viçosa region in Brazil, has a potential commercial value. However care should be taken in order not to mix unripe with ripe fruits during the extraction process, since their chemical compositions are entirely different.

Following the discovery that oils obtained from leaves collected from branches, with and without flowers, were significantly different, a further study was carried out to ascertain the effect of any seasonal variation on leaf essential oil composition.

The oil content in the leaves of S. terebinthifolius shows some minor changes throughout the course of one year but these changes were usually statistically insignificant (Figure 4). Oil content peaked (0.65-0.69\%) between March to September, and dipped (0.45$0.55 \%$ ) between October to February, which coincided with flowering and fruiting.

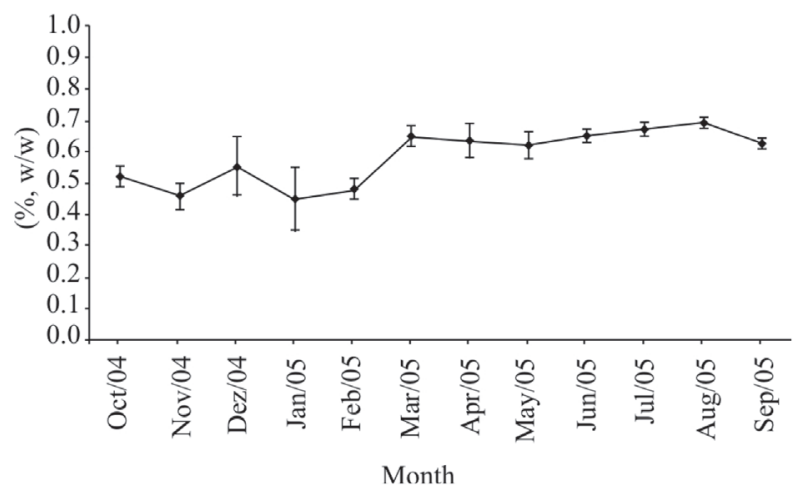

Figure 4. Changes in the essential oil content in the leaves during the course of one year, from October 2004 to September 2005

Seasonal variation in the oil composition of the leaves was also investigated and the results presented in Figures 5 and 6. The two major classes of compounds were the HM and HS. The percentage of HM varied greatly during the year, with a minimum during the months of March and April (around 12\%) and October and November (around $16.50 \%$ ). A maximum quantity of HM occurred in December (36.84\%), January (37.20\%) and July (42.05\%).

The HS also showed a considerable seasonal variation with a minimum content (approximately $47 \%$ in July) coinciding with the maximum of HM (Figure 5). In general, as observed in Figure 5 , an increase in the amount of HM is accompanied by a decrease in the HS content, and vice-versa. This observation is concordant with literature precedent ${ }^{33}$ which shows that the metabolism of these two classes of compounds is interconnected.

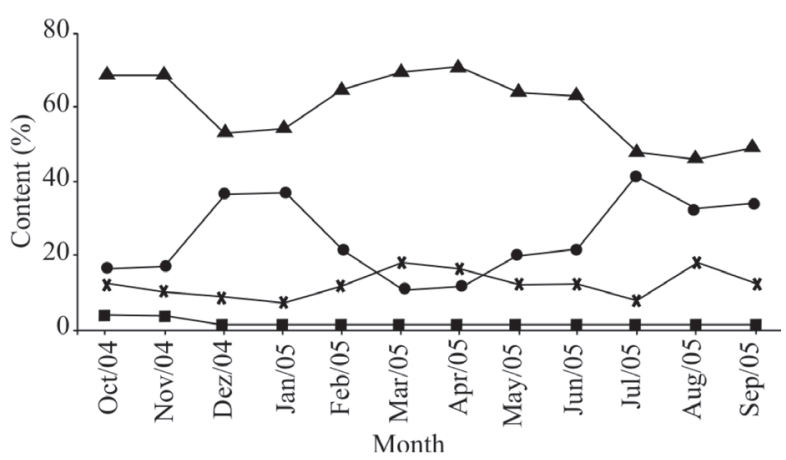

Figure 5. Changes in the relative percentage of $H M(\boldsymbol{\bullet}), O M(\boldsymbol{\square}), H S(\boldsymbol{\Lambda})$ and $\operatorname{OS}(\boldsymbol{*})$ in the essential oil from the leaves during the course of one year

The OS corresponded to the third most predominant group of compounds, with minimal production in the summer $(7.35 \%$ in January) and maximum in the winter (18.73\% in August). The OM were minor constituents from this oil, with levels ranging from $0.88 \%$ in April to $3.37 \%$ in October.

The variation in the relative abundance of the five major terpenes (p-cymene, $(Z)$ - $\beta$-ocimene, $(E)$-caryophyllene, germacrene $\mathrm{D}$ and bicyclogermacrene) from the volatile oil from leaves during the course of one year is represented in Figure 6.

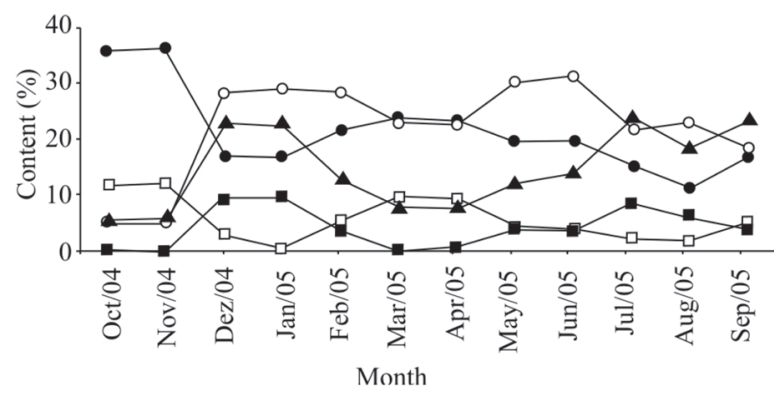

Figure 6. Changes in the relative percentages of p-cymene ( $\mathbf{\square}),(Z)-\beta$-ocimene ( $\mathbf{\Delta}),($ E)-caryophyllene $(\square)$, germacrene $D(\mathbf{O})$ and bicyclogermacrene $(\mathrm{O})$ in the volatile oil from the leaves during the course of one year

As the amount of germacrene D and $(E)$-caryophyllene decreases, there is a corresponding increase in the content of bicyclogermacrene, particularly from November to December (Figure 6). These results suggest that the biosynthesis of these terpenes is interrelated and a possible biosynthetic pathway for the formation of bicyclogermacrene, germacrene $\mathrm{D}$ and $(E)$-caryophyllene is presented in Figure 7. As reported in the literature, ${ }^{33-35}$ farnesylpyrophosphate (1, FPP) can be converted into the nonclassical carbocation $\mathbf{2}$, that can led to tertiary carbocations $\mathbf{3}$ or $\mathbf{9}$. Isomerization of $\mathbf{3}$ to $\mathbf{6}$, followed by intramolecular cyclopropane formation and proton ejection results in the formation of the more thermodynamically stable bicyclogermacrene $(\mathbf{8})$. The intermediate 9 can be transformed into $\mathbf{1 0}$, and a subsequent elimination of $\mathrm{H}^{+}$ results in the formation of $(E)$-caryophyllene (11). From this biosynthetic pathway, an increase in the formation of $\mathbf{8}$ has to be accompanied by a decrease in the accumulation of $\mathbf{5}$ and $\mathbf{1 1}$. 


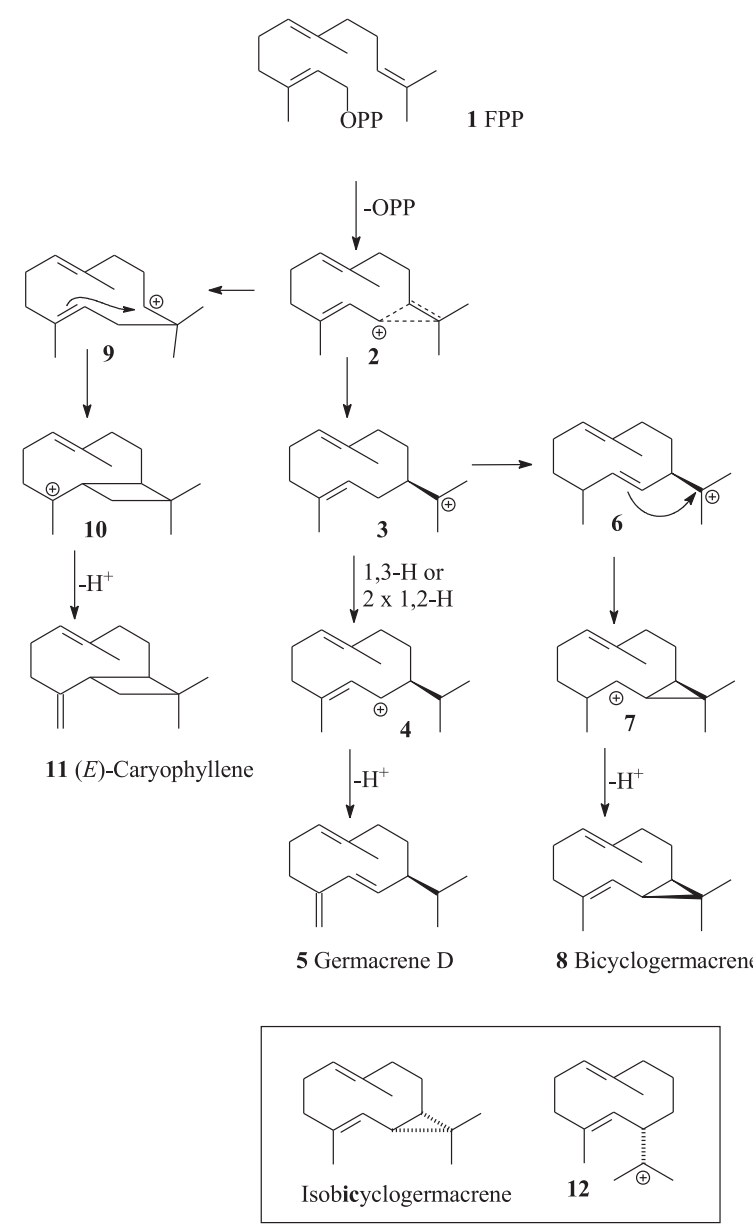

Figure 7. Proposed biosynthetic pathways ${ }^{33}$ for compounds 5,8 and 11 and structures of isobicyclogermacrene and the intermediate biogenetic cation 12

\section{Allelopathic effect}

The effects of essential oils from fresh leaves (LO), unripe (UFrO) and ripe (RFrO) fruits were evaluated upon radicle growth and seeds germination of Lactuca sativa (lettuce) and Cucumis sativus (cucumber). At the concentration of $1,000 \mu \mathrm{g} \mathrm{mL}^{-1}$, samples LO and UFrO caused small root inhibition on C. sativus (22.4 and $33.1 \%$, respectively) and no effect on $L$. sativa. Sample RFrO had no effect on both species. None of the samples caused any significant inhibition on seed germination on both plants tested. However, at the concentration of $10,000 \mu \mathrm{g} \mathrm{mL}^{-1}$, all samples caused significant inhibition on the radicle growth of both species and, in general, the three samples tested were more active in inhibiting the radicle growth for L. sativa (88.6-92.4\%) than for C. sativus (50.5-84.5\%). For L. sativa, no significant differences were observed in the activity upon application of the three samples (LO, UFrO, RFrO), by Tukey's test at 0.05 probability level.

For $C$. sativus, using the same test, no significant difference was observed between the activity of samples LO and UFrO. However, sample RFrO was significantly less active than the other two.

Sample LO, consists mainly of sesquiterpenes (83.60\%), included germacrene $\mathrm{D}$, bicyclogermacrene and $(E)$-caryophyllene, caused 88.6 and $78.7 \%$ inhibition on the radicle growth of $L$. sativa and $C$. sativus, respectively (at $10,000 \mu \mathrm{g} \mathrm{mL}^{-1}$ ). Also at $10,000 \mu \mathrm{g}$ $\mathrm{mL}^{-1}$, sample UFrO, also rich in sesquiterpenes (78.00\%), including $\alpha$-cadinol, $\beta$-cadineno and epi- $\alpha$-muurolol), caused 90.1 and $84.5 \%$ radicle growth inhibition of $L$. sativa and $C$. sativus, respectively. However, sample RFrO, behaved differently from the two previous terpene fractions, is composed mainly of monoterpenes (90\%), with major components being $\Delta^{3}$-carene, $\alpha$-phellandrene and $\beta$ phellandrene, $\alpha$-pinene and $\beta$-pinene. This sample caused considerable radicle growth inhibition in L. sativa (92.4\%), but its effect on $C$. sativus was halved $(50.5 \%)$.

At $1,000 \mu \mathrm{g} \mathrm{mL}^{-1}$ dose none of the three samples (LO, UFrO and $\mathrm{RFrO}$ ) caused any significant inhibition on the germination of neither $L$. sativa nor $C$. sativus. In contrast, at the higher dose of $10,000 \mu \mathrm{g} \mathrm{mL}^{-1}$, no significant inhibition was observed for $C$. sativus. At the same concentration, samples LO and UFrO, dominated mainly by sesquiterpenes, presented the same biological activity ( $75 \%$ of germination inhibition), while the RFrO sample, composed mainly of monoterpenes, was significantly more active $(90 \%$ of germination inhibition)

The allelopathic activity of both monoterpenes ${ }^{36,37}$ and sesquiterpenes ${ }^{38,39}$ is thoroughly documented. Amongst the active monoterpenes, there are a variety of oxygenated compounds especially nerol, citronellol, geraniol, linalool, terpinen-4-ol, $\alpha-$ terpineol, borneol, carvone, fenchone, pulegone, camphor, 1,8cineol, 1,4-cineol, carvacrol and ocimenone. ${ }^{18,20,22,36,40,41}$

It seems that the allelopathic activity showed by the oil of ripe fruits of S. terebinthifolius is not due to oxygenated monoterpenes, since these are present in very low concentration in this oil, with respect to the hydrocarbon monoterpene content. In the case of $S$. terebinthifolius, both essential oils rich in sesquiterpenes (LO and $\mathrm{UFrO}$ ) and that rich in monoterpenes (RFrO) showed significant radicle growth inhibition for $L$. sativa and $C$. sativus, and significant inhibition of germination of L. sativa. Although it is not yet possible to attribute such activities to any specific constituent of these oils, it is relevant that major components, or combination of components, from the oil of unripe fruits are sesquiterpenes derived from cadinene $(\alpha$-cadinol, $\beta$-cadineno, $\delta$-cadineno, $\gamma$-cadineno, epi- $\alpha$ muurolol), the same compounds that presented allelopathic activity as reported in the literature. ${ }^{38}$

In conclusion, although we were unable to locate any literature on the chemical composition requirements for the commercial volatile oil of $S$. terebinthifolius, we believe that the oil obtained by hydrodistillation from $S$. terebinthifolius ripe fruits, found in Viçosa (Brazil), can be used as a substitute for the commercial oil obtained by supercritical fluid extraction. Care should be taken in the processing stage in order to avoid the mixture of ripe and unripe fruits $S$. terebinthifolius, as their chemical constitution are very different. Importantly, the reported allelopathic activity observed for S. terebinthifolius can, in part, be explained by the volatile oil produced in their leaves and fruits.

\section{ACKNOWLEDGEMENTS}

CNPq for research fellowships (LCAB, AJD) and FAPEMIG for financial support. Prof. A. L. Pinheiro, for providing us with the vegetal material and F. C. Chaves (Rutgers University, USA) for valuable suggestions and emendations the manuscript.

\section{REFERENCES}

1. Morton, J. F.; Econ. Bot. 1978, 32, 353

2. Williams, D. A.; Overholt, W. A.; Cuda, J.; Hughes, C. R.; Molec. Ecol. 2005, 14, 3643 .

3. Liogier, H. A.; Descriptive flora of Puerto Rico and adjacent islands: Spermatophyta Editorial de la Universidad de Puerto Rico: Rio Piedras, PR, 1988, Vol. 2.

4. Lenzi, M.; Orth, A. I.; Rev. Bras. Frutic. 2004, 26, 198.

5. Lorenzi, H.; Árvores Brasileiras - Manual de Identificação e Cultivo de Plantas Arbóreas Nativas do Brasil, Plantarum: Nova Odessa, 1992, Vol. 1

6. Velásquez, E.; Tournier, H. A.; Buschiazzo, P. M.; Daavedra, G.; Schinella, 
G. R.; Fitoterapia 2003, 74, 91.

7. Degaspari, C. H.; Waszczynskyj, N.; Santos, R. J.; Vis. Acad. 2004, 5, 83.

8. Amorim, M. M. R.; Santos, L. C.; Rev. Bras. Ginecol. Obst. 2003, 25, 95

9. Melo Jr, E. J. M.; Raposo, M. J.; Lisboa Neto, J. A.; Diniz, M. F. A.; Marcelino Junior, C. A. C.; Sant'ana, A. E. G.; Phytomedicine 2002, 9, 109.

10. Ibrahim, M. T.; Fobbe, R.; Nolte, J.; Bull. Fac. Pharm. 2004, 42, 289.

11. Guerra, M. J. M.; Barreiro, M. L.; Rodriguez, Z. M.; Rubalcada, Y.; Rev. Cub. Plant. Med. 2000, 5, 5.

12. Schmourlo, G.; Mendonça-Filho, R. R.; Alviano, C. S.; Costa, S. S.; J. Ethnopharmacol. 2005, 96, 563.

13. Matos, F. J. A.; O formulário fitoterápico do professor Dias da Rocha, $2^{\mathrm{a}}$ ed., UFC: Fortaleza, 1997.

14. Carvalho, M. C. R. D.; Barca, F. N. T. V.; Agnez-Lima, L. F.; Medeiros, S. R. B.; Environ. Mol. Mutagen. 2003, 42, 185.

15. Morgan, E. C.; Overholt, W. A.; J. Torrey Bot. Soc. 2005, 132, 11.

16. Ewe, S. M. L.; Sternberg, L. S. L.; Forest Ecol. Manag. 2003, 179, 27.

17. Ewe, S. M. L.; Sternberg, L. S. L.; Oecologia 2002, 133, 441.

18. Scrivanti, L. R.; Zunino, M. P.; Zygadlo, J. A.; Biochem. Syst. Ecol. 2003, $31,563$.

19. De Feo, V.; De Simone, F.; Senatore, F.; Phytochemistry 2002, 61, 573.

20. Angelini, L. G.; Carpanese, G.; Cioni, P. L.; Morelli, I.; Macchia, M.; Flamini, G.; J. Agric. Food Chem. 2003, 51, 6158.

21. Tzakou, O.; Gani, A.; Economou, G.; Yannitsaros, A.; J. Essent. Oil Res. 2004, 16, 425.

22. Romagni, J. G.; Allen, S. N.; Dayan, F. E.; J. Chem. Ecol. 2000, 26, 303.

23. Singh, A. K.; Singh, J.; Gupta, K. C.; Brophy, J. J.; J. Essent. Oil Res. 1998, $10,697$.

24. Jamal, Y.; Agusta, A.; Majalah Farmasi Indonesia 2001, 12, 135.
25. Chowdhury, A. R.; Tripathi, S.; Ind. Perfum. 2001, 45, 257

26. Malik, M. S.; Mahmud, S.; Sattar, A.; Pak. Sci. Int.(Lahore), 1994, 6, 351.

27. Silva, A. F.; Barbosa, L. C. A.; Nascimento, E. A.; Casali, V. W. D.; J. Essent. Oil. Res. 2000, 12, 725.

28. Standards Engineering Practices Data, Moisture Measurement-Forages. American Society of Agricultural Engineers, 2000, ASAE S358.2 DEC99.

29. Adams, R. P.; Identification of essential oil components by gas chromatography/ mass spectroscopy, Allured Publishing Corporation: Illinois, 1995.

30. Martins, F. T.; Santos, M. H.; Pólo, M.; Barbosa, L. C. A.; Quim. Nova 2006, 29, 1203.

31. Barbosa, L. C. A.; Demuner, A. J.; Alvarenga, E. S.; Oliveira, A.; KingDiaz, B.; Lotina-Hennsen, B.; Pest. Manage. Sci. 2006, 62, 214.

32. Waterman, P. G. In Volatile oil crops: their biology, biochemistry and production Hay, R. K. M.; Waterman, P. G., eds.; Lorigman Group: Avon, 1993, cap. 3, p. 47-61.

33. Hackl, T.; Konig, W. A.; Muhle, H.; Phytochemistry 2004, 65, 2261.

34. Bulow, N.; Konig, W. A.; Phytochemistry 2000, 55, 141.

35. Jiang, J.; He, X.; Cane, D. E.; J. Am. Chem. Soc. 2006, 128, 8128.

36. Fischer, N. H.; Williamson, G. B.; Weidenhamer, J. D.; Richardson, D. R.; J. Chem. Ecol. 1994, 20, 1355.

37. Vaughn, S. F.; Spencer, G. F.; Weed Sci. 1993, 41, 114.

38. Baruah, N. C.; Sarma, J. B.; Sarma, S.; Sharma, R. P.; J. Chem. Ecol. 1994, 20, 1885.

39. Picman, A. K.; Biochem. Syst. Ecol. 1986, 14, 355.

40. Reynolds, T.; Annals Bot. 1987, 60, 215.

41. Vaughn, S. F.; Spencer, G. F.; Weed Sci. 1996, 44, 7. 